\section{DESQUAMATION FROM SWEATING.}

\section{JAY FRANK SCHAMBERG, M.D.} PHILADELPHIA.

There are commonly observed in medicine manifestations of morbid processes which are deemed so trivial as scarcely to warrant description and recording. Such must be the case with the condition here referred to, for in one grade or another it is a most common affection.

Particularly during the warm months of the year. and in persons who perspire on the palms of the hands even in the cold months, there is frequently seen in these regions small rings of desquamation. The process is first observed as a pin-point-sized whitish scaling which, as a result of peripheral extension, produces an annular exfoliation of the superficial horny layers. One or more of these patches may be present. Through spreading of the margin of the peripheral scaling, neighboring rings coalesce, with the production of larger serpiginons patches (see illustration). In this manner an extensive desquamation of the palms may result. The condition is limited to the palmar and lateral surfaces of the fingers and hands. At times, however, the soles of the feet may be similarly involved.

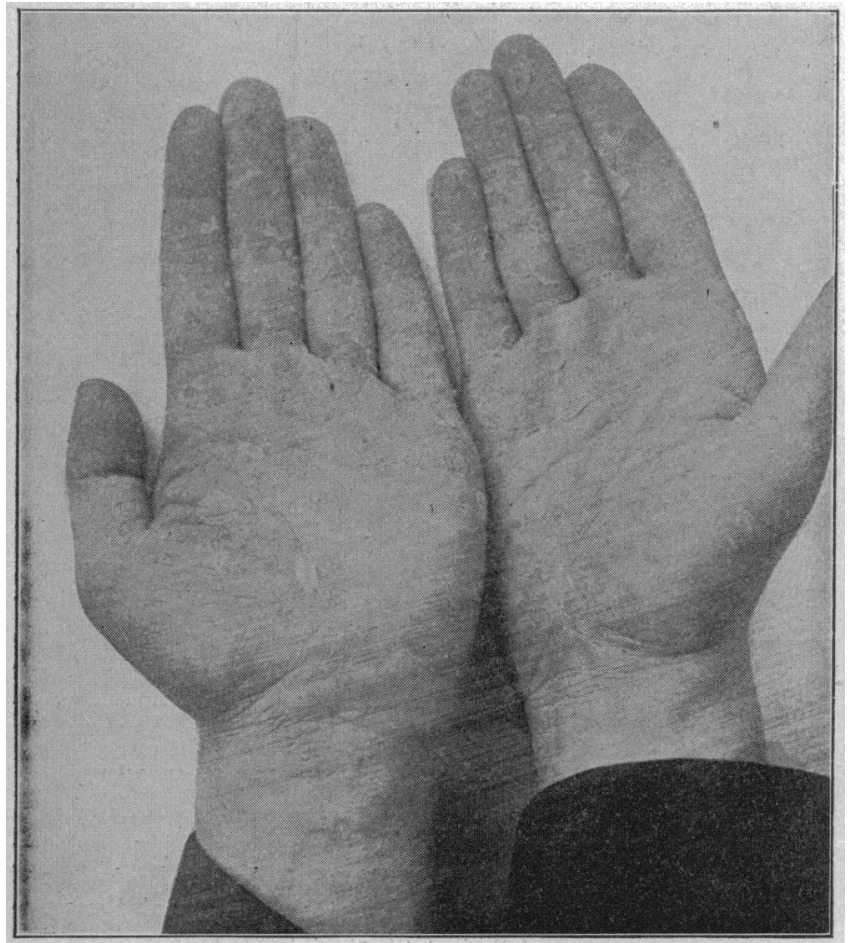

Fig. 1.-Desquamatio sudoralis, or desquamation from sweating.

I write this communication because recently I have seen several school children who have been excluded from the public schools on suspicion that the scaling of the palms was of scarlatinal origin. Given a child who has been absent from school because of some ailment and, on resuming school attendance exhibits scaling palms and perhaps soles, the importance of excluding scarlet fever in the diagnosis of the antecedent illness is apparent. I have also seen adults who were rather alarmed by the extensive scaling of their hands. As far as I am aware, there is no description of this condition in text-books on dermatology or in contributions to periodicals.

I believe that the scaling is due to infiltration of the superficial horny layer of the skin with sweat, perhaps caused by obstructed sudoriferous ducts. 'The transuded sweat then seems to become absorbed and desquamation takes place. Sometimes the appearance of a pin-pointsized reddish spot precedes the desquamation. In pronounced cases small vesicles are present, although the condition is quite distinct from dysidrosis or cheiropompholyx. There are no subjective symptoms.

The condition is apparently allied to that which gives rise to sudamina, the difference in the appearances being due to the thickness and dryness of the horny laver of the palms as contrasted with that elsewhere.

As the desquamation is the conspicuous feature of the affection, and as it is convenient to have some appelation for the condition, I would suggest the name "sweat desquamation" or "desquamatio sudoralis."

1922 Spruce Street.

\section{A PRACTICAL MILK COOLER.}

\section{H. J. GERSTENBERGER, M.D.}

Medical Director of the Babies' Dispensary. CLEVELAND, OHIO.

While trying to improve the cooling scheme in use at the farm supplying the Babies' Dispensary with milk, a cooling can was devised which has enabled us to dispense with pasteurization and sterilization during the summer. The cooling can, which accommodates a fivegallon milk-can, is made of galvanized iron No. 20 . It is 22 inches high and has a diameter of 14 inches. The cover is hinged on, fits snugly, and can be locked to the can (see illustration).

About 3 to 5 minutes before putting the milk into the milk-can the can is placed in this cooler. A mixture of ice and salt, such as is used by the ice-cream manufac-

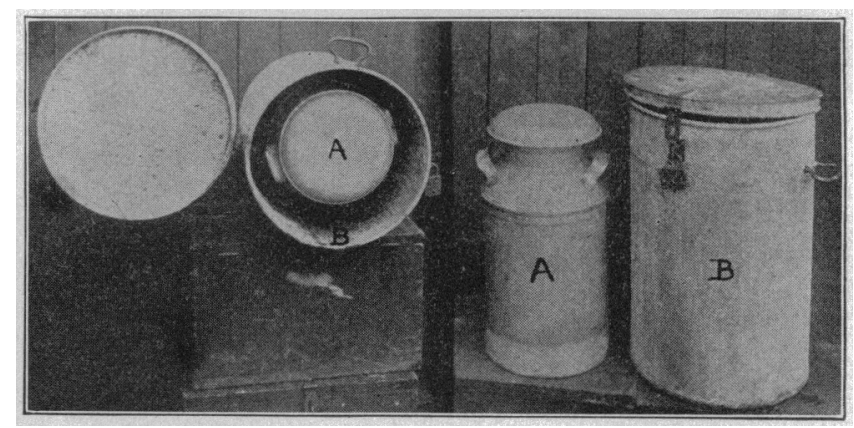

A practical milk cooler. A, milk-can; B, cooling-can.

turers, is then packed around the milk-can to the highest point which will be reached by the milk. The milk is then allowed to run from the strainer and cooler in use at the farm directly into the iced can. The milkcan cover is then put on and the cooling-can also is temporarily closed. 'The can is placed in a shady and cool place. After about 30 to 40 minutes the covers are carefully removed and the milk is carefully but thoroughly stirred with a clean, long spoon or other utensil. Then the can is tightly closed; if necessary, some more ice can be put around it and the cooling-can locked and shipped.

At every icing the following precaution must be observed in order to avoid getting ice and salt in the milk. After the milk-can has been placed in the cooler a "cap" is placed over the top of the closed milk-can before the ice and salt are packed around it. The "cap" is made of galvanized iron No. 26 and is 10 inches in diameter and 5 inches high. It really is a simple pan of the size 
required to cover the head and neck of the milk-can. It has served our purpose well.

We have been able by the use of this cooler to prevent practically any rise in the bacterial content of the milk from the time it leaves the strainer. About 30 minutes after the milk has been put into the cans and cooled in this manner, the temperature will be $50 \mathrm{~F}$. or below and will remain so for from 3 to 5 hours. About 25 to 35 pounds of ice are required to cool five gallons of milk efficiently. The salt used costs $\$ 7$ per ton.

If the cooler in use at a farm lowers the milk to about 45 $\mathrm{F}$., it may be possible to keep the temperature below $50 \mathrm{~F}$. by simply packing the can in ice without salt. By a little experience one can soon learn-using the thermometer-whether ice alone or both ice and salt, and whether much or little of one or the other, is necessary to get the low temperature desired. This simple apparatus gives every farmer the means of cooling his milk to $50 \mathrm{~F}$. or below at a reasonable cost. As soon as the weather is cooler less ice and salt must be used or the milk will be frozen, as has happened once in our experience.

\section{NAILING THE LOWER EPIPHYSIS OF THE RADIUS.}

REFORT OF A CASE.

\section{H. A. HAUBOLD, M.D.}

Clinical Professor in Surgery, New York Lniversity and Bellevue IIospital Medical College: Surgeon. to Harlem Hospital. NEW YORK CITY.

The case here reported was diagnosticated before the skiagram was submitted, as it presented no great problem. 'T'he onc point which ultimately resulted in a favorable outcome, however, was brought out by a study of the skiagram and the measure for relief decided on.

History.-C. N., aged 15, was admitted to Harlem Hospital. July (6, 1908, with a history of having fallen from a rapidly moving trolley car. In an effort to save himself he held the riglit hand forward and the force of the fall was received on the palm. The ambulance surgeon who saw the boy soon after the injury diagnosticated a fracture of the lower end of the maliss with lateral displacement. The boy had also sustained a small sealp wound and some minor contusions. The latter wre of little import, howerer, and after an unsuccessfuI attempt at reduction of the deformity at the forearm the patient was admitted to the hospital.

Examination.-After the members of the house staff and I hat made an examination and a second attempt at reduction by manipulation was made, the forearm was skiagraphed by Dr. W. II. Stewart. The results are shown in Figures 1, 2 and 3. Figure I shows the lower radial eptphysis displaced to the radial side and a small portion of the shaft of the bone earried with it. The ease was regarded as one of epiphyseal separation with lateral displacement, and after the second attempt to effect reduction had failed the patient was anesthetized and a forcible attempt at reduction made. This provel ineffectual. however, despite the fact that the limb was placed on a sandbag and the lower fragment sharply struck with a mallet.

Close study of the skiagram led to the conclusion that the displacement was the result of the pushing of the lower end of the shaft toward the ulna, and that this, rather than the radial displacement of the lower fragment, was the cause of the deformity. This view was strengthened by the over-lapping of the radius on the ulna. It is this point which em. phasizes the value of skiagraphy in this class of cases.

Treatment.-On July 10, 1908, a curved incision with the concavity downward was made over the radial side of the fracture and the flap turned downward. This incision was made to obviate the presence of the scar at the site of the

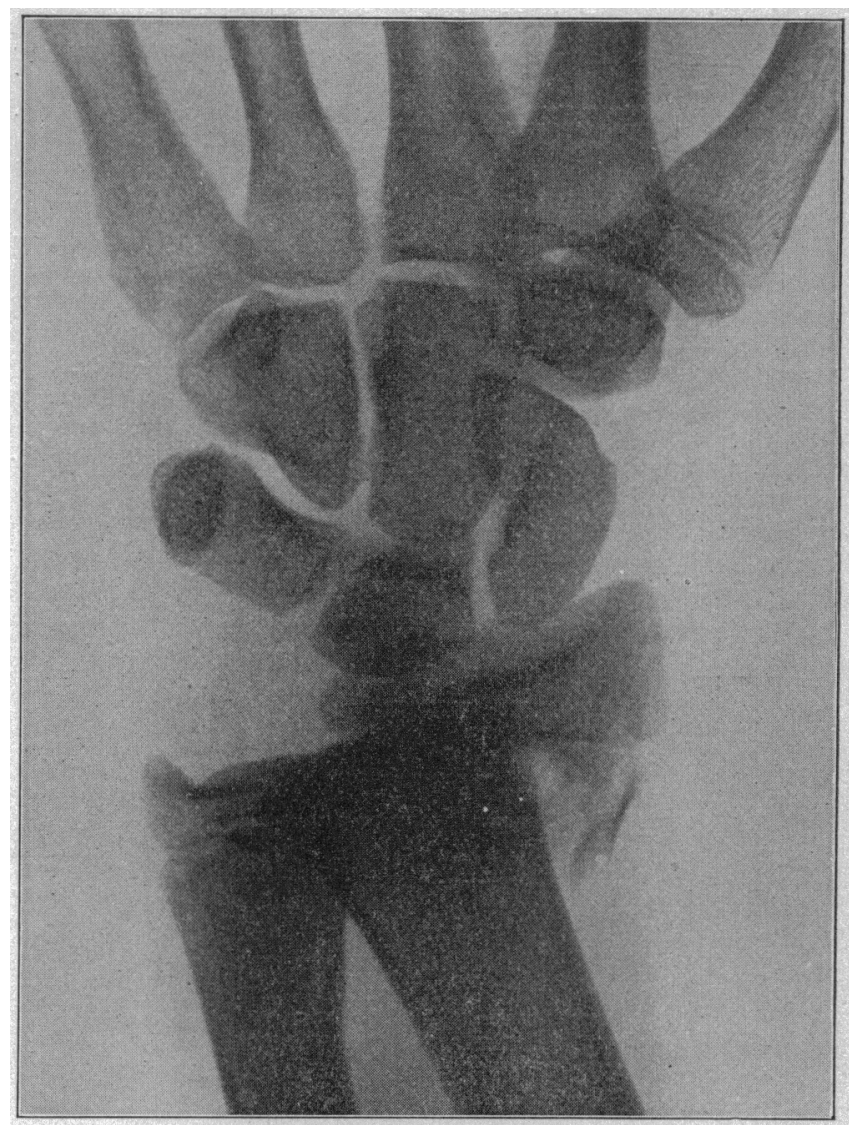

Fir. 1.-Skiagram showing radial epiphysis displaced to the radial side and a small portion of the shaft of the bone carried
with it.

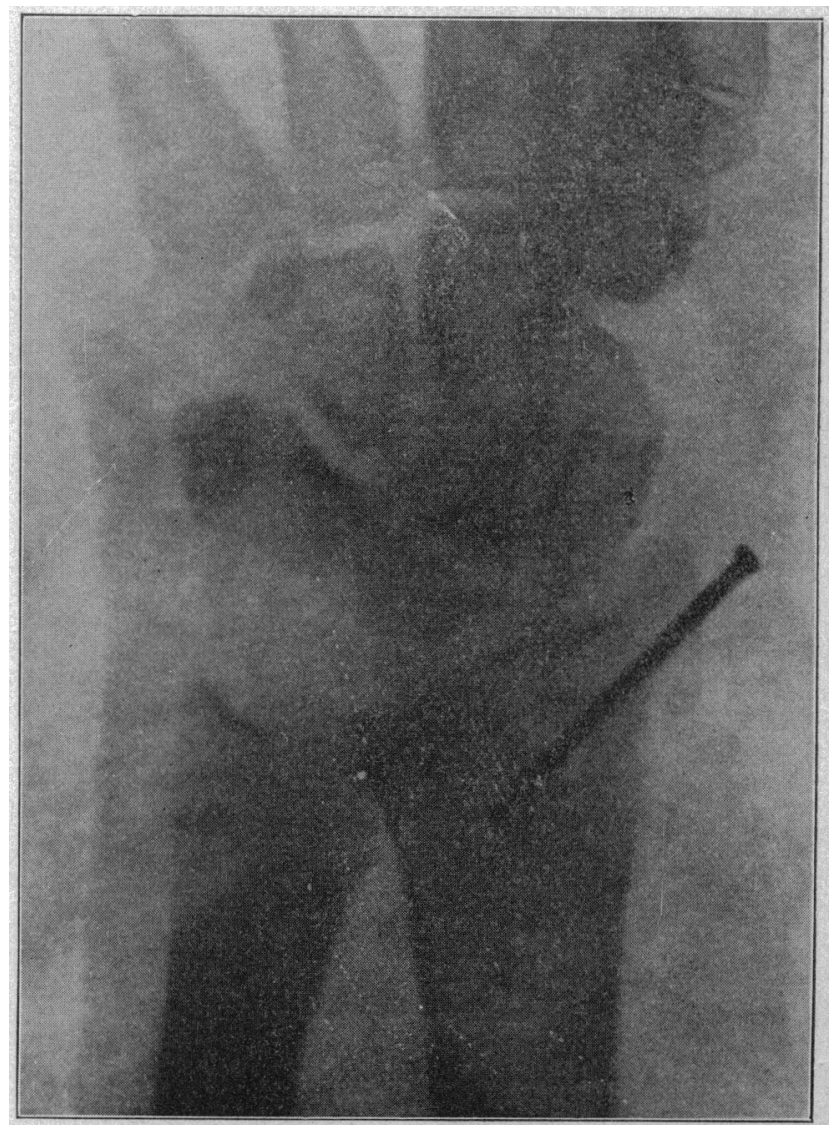

Fig. 2.-Sklagram showing the detached fragment nailed to the shaft of the bone. 